\title{
Epistemologia do Design Afirmativo
}

\section{Epistemology of Affirmative Design}

\author{
SANTOS, Sandro; Doutorando; PUC-Rio e UFRRJ \\ sandroslopex@yahoo.com.br \\ NOJIMA, Vera; Doutora; PUC-Rio \\ nojima@puc-rio.br
}

\section{Resumo}

Trata-se de um ensaio sobre a produção do design a partir de uma visão crítica baseada nas estéticas africana e afro-brasileira. Para embasar a reflexão, o texto apresenta como a construção da imagem do negro foi depreciada, através de políticas públicas estatais por interesse das elites brasileiras e demonstra o posicionamento dos movimentos negros como peça fundamental na desconstrução desse imaginário e ressignificação da imagem do negro na atualidade. Essa imagem associada a um design focado numa cosmovisão africana tem a intenção de contribuir para a melhoria das condições da população negra no país, o que chamamos de Design Afirmativo.

Palavras Chave: ação-afirmativa; racismo; design e afrocentricidade.

\begin{abstract}
The textmakes a essayaboutthe design producedfrom a critical view inspiredby Africanand AfroBrazilianknowledge. With the intention of helping reflection, the article presentes the construction of how the image of the black has been depreciated, through state in the interest of the Brazilian elites, and de monstrates the position of the black movements as a fundamental piece in the deconstruction of this imaginary and re-signification of image of the current black pleople. This image presente eassociated with a design focuse don this African world vie wisintended to contribute to the improvement of the conditions of the black population in the country.
\end{abstract}

Keywords: Affirmativeaction, racism, design, afrocentricity. 


\section{Introdução}

A desigualdade de oportunidades entre brancos e negros em nosso país é resultado de uma política histórica do estado brasileiro que utiliza o "mito da democracia racial" ${ }^{1}$ como uma de suas bases de manutenção de poder sobre os negros no Brasil.

Essa assimetria resulta em reinvindicações por cidadania pela população negra durante toda história do país, da colonização até os dias de hoje. Um dos movimentos que serviu de exemplo para os Movimentos Negros ${ }^{2}$ da atualidade no Brasil foi a luta pelos direitos civis nos Estados Unidos nos anos 1960. Esse momento da história americana desenvolveu o conceito de ação afirmativa, em que se exigia do Estado políticas públicas com o objetivo de melhorar as condições da população negra daquele país. Esse conceito tornou-se um referencial para vários países no mundo. A doutora Sabrina Moehleche em seu artigo conceitua o termo:

Num esforço de síntese e incorporando as diferentes contribuições, podemos falar em ação afirmativa como uma ação reparatória/compensatória e/ou preventiva, que busca corrigir uma situação de discriminação e desigualdade infringida a certos grupos no passado, presente ou futuro, através da valorização social, econômica, política e/ou cultural desses grupos, durante um período limitado. (2002, p.203).

Essa ideia, além do combate sistemático à discriminação, usa a valorização da diversidade cultural como elemento de base para a identidade positiva para esses grupos. Esse conceito foi sendo implementado no Brasil a partir da redemocratização do país, ocorrida nos anos de 1980, devido a pressão dos movimentos negros daquele período. Um exemplo disso foi a "Marcha Zumbi contra o Racismo, pela cidadania e pela vida", que em 1995, na data de aniversário de 300 anos da morte de Zumbi dos Palmares, pressionou e entregou ao presidente da república uma carta com reivindicações contra o racismo, pela igualdade e a vida.

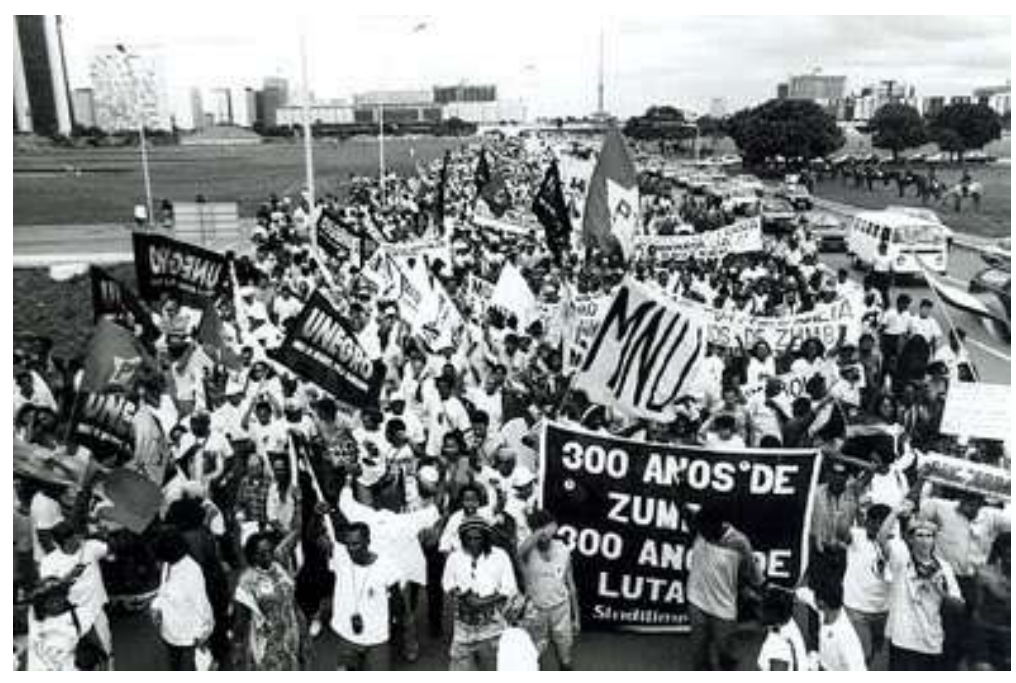

\footnotetext{
${ }^{1}(\ldots)$, elaborou-se, com efeito, no bojo da Revolução de 1930 (...) Nem importa a identificação de diversos intelectuais - Gilberto Freyre à frente - que Ihe deram acabamento científico e literário: a crença na democracia racial decorria do senso-comum brasileiro, naquelas circunstâncias históricas; e, ao mesmo tempo, estava entretecida a outros conjuntos de imagens idealizadas, como o da história incruenta, o da benignidade da nossa escravidão, o da cordialidade inata do brasileiro, o do destino manifesto etc. (SANTOS, 1985, p.287).
}

2 (...) considerando a multiplicidade de estratégias, ações e formas de organização, a utilização do termo no plural, "movimentos negros", estaria correta. (PEREIRA, 2010, p.81). 
Imagem 1 - Marcha Zumbi contra o Racismo, pela cidadania e pela vida.

A pressão resultou no reconhecimento de injustiças históricas pelo Estado Brasileiro. Isso influenciou os rumos da luta contra o racismo no país, pois revelou o racismo estrutural ${ }^{3}$ da nação para toda a sociedade.

Na verdade, em novembro de 1995, na ocasião das comemorações dos 300 anos da morte de Zumbi dos Palmares, durante a Marcha Nacional Zumbi dos Palmares Contra o Racismo, Pela Cidadania e a Vida, o presidente Fernando Henrique Cardoso já havia exposto seu ponto de vista em relação ao assunto, afirmando que o Brasil ainda discriminava em larga escala à população negra. Um dos desdobramentos da marcha foi o estabelecimento do Grupo de Trabalho Interministerial para a Promoção da População Negra (GTI), sob a coordenação do acadêmico e ativista negro Hélio Santos, a fim de que tal grupo pudesse formular estratégias de políticas públicas capazes de reduzir as desigualdades raciais. (SANTOS, 2005, p.34).

A pressão dos movimentos negros sobre o poder público resultou, a partir dos anos 2000, em políticas de ações afirmativas no país, colocando o tema no foco da discursão nacional de maneira bem presente. A Criação da Fundação Cultural Palmares, da Secretaria de Políticas de Promoção da Igualdade Racial (SEPPIR), da implementação das cotas nas universidades, das Lei 10.639/03 e 11.645/08, dos editais culturais para criadores e produtores negros (Curta-afirmativo, Arte Negra, FBN: Autores Negros, Pesquisadores Negros e Ponto de leitura) são exemplos desse avanço. Apesar disso, o Estado brasileiro ainda resiste em implementar políticas de inclusão por critério raciais, preferindo critérios socioeconômicos para combater o racismo. Apenas as oportunidades econômicas, não reparam uma discriminação histórica, é necessária uma ressignificação que passa também por questões simbólicas. Só a existência do racismo pode explicar que haja brancos e negros de mesmo nível socioeconômico, ainda apresentando desigualdades entre eles (DIMENSTEIN, 2004).

É importante destacar que o avanço nas questões sociais não elimina a discriminação racial, pois ela tem várias especificidades.

\begin{abstract}
Uma política que se baseia em critérios unicamente sociais para responder a disparidades de ordem racial é incapaz de solucionar de modo eficiente a discriminação racial ou a estratificação socioeconômica, pois não consegue desfazer as interconexões de raça e classe. Em ambos os contextos, que experimentaram uma história de escravidão e discriminação racial, o problema racial está associado ao social e um aspecto não pode ser solucionado sem que se considere também o outro (HERMANDEZ apud MOEHLECHE, 2002, p.215).
\end{abstract}

A escolha governamental que privilegia unicamente as diferenças de renda é uma maneira sutil de negar a discriminação racial no Brasil e manter a relação de poder existente. Isso vai, de acordo com que o geógrafo e pesquisador Milton Santos (1998) alega, "que no Brasil, nem todos são igualmente cidadãos", o autor diz haver "os que querem ser cidadãos e os que querem privilégios".

\footnotetext{
${ }^{3}$ Por sua ampla e complexa atuação, o racismo deve ser reconhecido também como um sistema, uma vez que se organiza e se desenvolve através de estruturas, políticas, práticas e normas capazes de definir oportunidades e valores para pessoas e populações a partir de sua aparência3 atuando em diferentes níveis: pessoal, interpessoal e institucional. (GELEDÉS, P.11)
} 
O avanço para a igualdade de condições de grupos marginalizados passa por deliberações em diversos campos: econômicos, sociais, culturais e políticos. Exatamente nesse mosaico que o design pode atuar, por se tratar de um campo interdisciplinar e transversal. Ele pode fazer a mediação entre essas diversas ações, por trabalhar no campo dos signos com uma forte possibilidade de concretizar novas ideias, como o Design Afirmativo.

\section{Identidades e a relação com o Design}

Na segunda metade do século XX, o design passa a ser mais orientado para questões locais, gerando um novo posicionamento no campo relacionado às questões da atualidade, ambiental, tecnológica e social. Essas demandas surgem com o intuito de promover melhorias e justiça social, mas, ainda assim, essas orientações não dão conta das demandas raciais existentes. No design, persiste a necessidade de levar em conta o ponto de vista negro, trazendo sua cultura, mitologia e espacialidade.

No caso do Brasil, a importância de um design com um aspecto político que pense essas questões raciais é de extrema importância, a necessidade de um design que se oponha ao design valoriza o glamour de uma ideologia do embranquecimento ${ }^{4}$, de uma elite brasileira alinhada a um desenvolvimento de um conjunto de instituições internacionais, que usam a invisibilidade do indivíduo negro como estratégia de poder.

Porém, o aumento das discussões raciais provocadas pelos movimentos negros vem construindo embates também no campo das representações culturais e simbólicas. 0 reconhecimento da matriz-afrobrasileira, sem a estratégia de mestiçagem imposta pelas elites para a sua aceitação, é o resgate da simbologia que está permanentemente exposta na periferia. O uso do turbante, por exemplo, além de um ornamento é uma referência histórica. $O$ significado está em outro lugar que não, na hierarquização provocada pelo eurocentrismo.

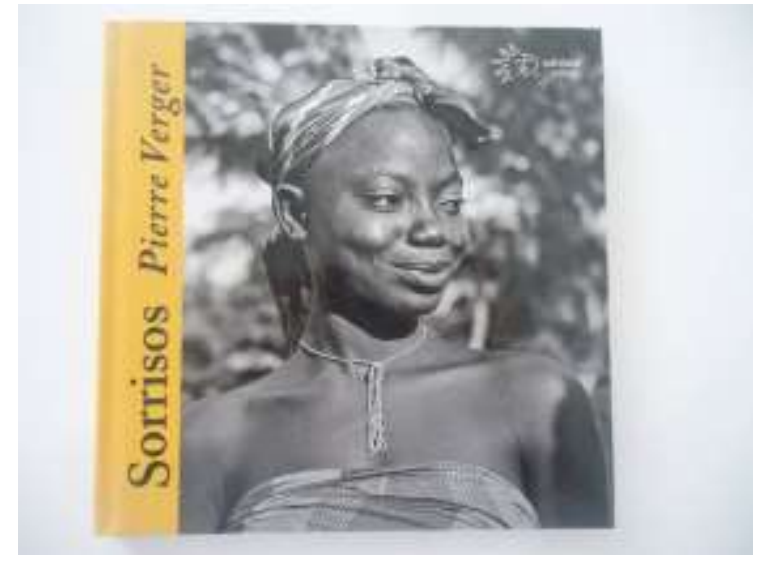

Imagem 02 - Capa do livro do fotografo Pierre Verger

\footnotetext{
${ }^{4}$ Passou, portanto, a significar a capacidade da nação brasileira (definida como uma extensão da civilização europeia em que uma nova raça emergia) de absorver e integrar mestiços e pretos. Tal capacidade requer, de modo implícito, a concordância das pessoas de cor em renegar sua ancestralidade africana ou indígena. "Embranquecimento" e "democracia racial" são, pois conceitos de um novo discurso racialista. (GUIMARÃES, 1999, p.53).
} 


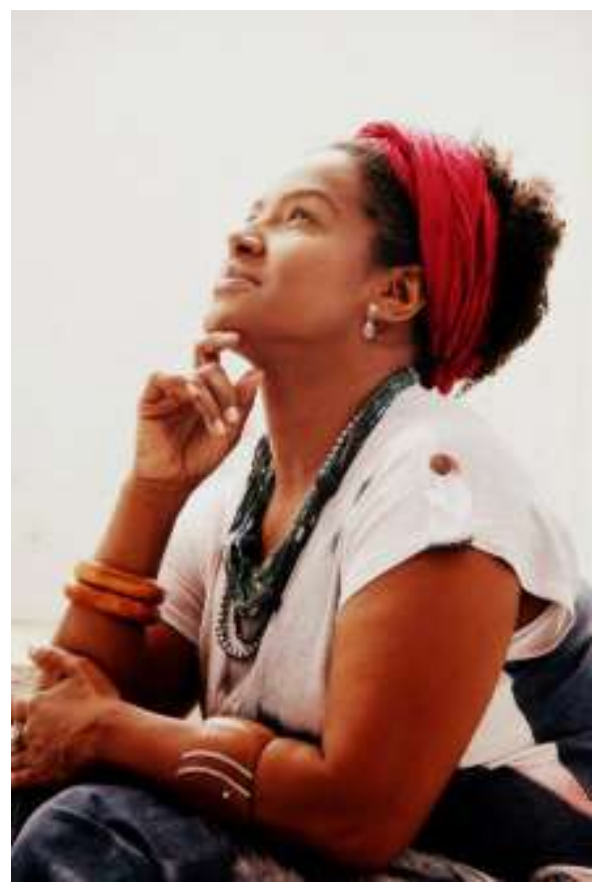

Imagem 03 - Turbante na atualidade

Esse processo de construção de uma identidade negra positiva, resultará em códigos poderosos com o qual a comunidade afro-descendente cada vez mais se empodera e se reconhece.

Tão poderosos são nossos códigos, aliás, que construímos a partir deles versões alternativas da chamada realidade, mundos paralelos, múltiplas experiências do aqui e agora, as quais convencem, comovem e tornam-se "reais" à medida que acreditamos coletivamente em sua eficácia. (FLUSSEM, 2007, p.14).

A estética, a história e os conhecimentos africanos, afro-brasileiros e da Diáspora ${ }^{5}$ são pontos importantes na construção de um design que coloca estas pessoas no mundo através de formas que valorizem e amplifiquem a sua corporeidade, subvertendo a relação de poder e as instâncias de legitimação.

O corpo sendo o principal "elemento social" de diferenciação entre os indivíduos, que através da cultura, usam os sistemas de representação desenvolvidos para classificá-los e hierarquizá-los, podendo ser usado como elemento de poder, que ao ser alinhada a uma identidade única, representa mais a diferença e a exclusão do que o signo de uma unidade idêntica (Hall, 2000).

Hoje há um novo paradigma, baseado na representação que cria significados diversos devido o declínio das "velhas identidades". Essa nova orientação se opõem a uma identidade unificada, integral e homogênea. Essa identificação contemporânea, também identificada como tardia, se apresenta fragmentada e múltipla. O sujeito sofre um deslocamento, o que muda a nossa identidade pessoal.

\footnotetext{
${ }^{5} \mathrm{~A}$ diáspora africana, que não pode ser pensada minimamente como a dispersão forçada de africanos e seus descendentes pelos países ocidentais, unificados pelo trauma da escravidão, traz como característica uma complexa rede de solidariedade e compartilhamento de experiências que não se pautam pela genealogia ou por uma origem territorial comum. (Pinheiro, 2015, p.11)
} 
Essa concepção aceita que as identidades tardia, cada vez mais fragmentadas e fraturadas; que elas não são nunca singulares, mas multiplamente construídas ao longo de discursos, práticas e posições que podem se cruzar ou ser antagônicos. As identidades estão sujeitas a uma historicização radical, estando constantemente em processo de mudança e transformação. (HALL, 2000, p.108).

Nessa transformação, a cultura é peça importante para que esse sentimento de presença na sociedade se torne evidente, através dessa autenticidade.

\section{Conceito de Design Afirmativo}

Nesse contexto, onde os sistemas de significações se multiplicam, em que a diferença e o antagonismo se colocam, se apresenta um design que dissemina conhecimentos afros e afrodiaspóricos, rompendo com o pensamento colonizador, que ainda hoje, vê a população negra de forma degenerada por causa de sua cor de pele. É importante ressaltar que os padrões ocidentais são gestados, difundidos, defendidos através de políticas econômica, culturais e sociais da Europa e dos Estados unidos da América. (Noguera, 2014).

"O discurso colonial europeu manteve sua força e poder por meio do discurso da dominação colonial e da desmoralização dos povos colonizados onde a supremacia da raça branca europeia sobrepujava todos os outros que desta não faziam parte." (SILVA, p.266, 2014)

Segundo a pesquisadora Joyce Gonçalves da Silva (2014), essas ausências referenciais provocadas pelo discurso colonizador, provocam na formação identitária dos povos, uma percepção negativa e exótica do corpo negro. No caso do Brasil, essa imagem negra é restrita aos estereótipos da sexualidade, malandragem e criminalidade. No intuito de contribuir para uma ressignificação da imagem do negro é que diversas áreas do conhecimento vêm desenvolvendo novas formas de pensar o sujeito.

A interdisciplinaridade intrínseca do campo do design permite alianças com áreas como antropologia, sociologia, psicologia e filosofia, nas quais há uma busca da relação histórica com a atividade prática, reforçando uma conotação ideológica de um outro ponto de vista que vise contribuir para a construção de um reforço e de uma identidade, na busca de uma equidade social. Esse discurso multimodal, vai permear a prática, no qual tem a intensão de, através do design, contribuir para a eliminação das assimetrias através da não naturalização da ideologia do embranquecimento que é usada de forma hegemônica no domínio econômico, político e cultural na sociedade brasileira.

(...) as ideologias são significações / construções da realidade (o mundo físico, as relações sociais, as identidades sociais) que são construídas em várias dimensões das formas / sentidos das práticas discursivas e que contribuem para a produção, a reprodução ou a transformação das relações de dominação ( Fairclough, 2008, p.117 apud OLIVEIRA, 2013, p.299)

Essa ideia vai ao encontro do que Bomfim (COUTO, 2014) afirma, que o design é um grande instrumento de materialização e perpetuação de ideologias, que molda os indivíduos através dos objetos que configura. Por esse motivo a produção de produtos e comunicação de outro ponto de vista é importante.

A ideia de Afirmativo aqui apresentada tem uma relação com as políticas de ação afirmativas, pois essas têm uma grande diversidade de sentidos, mas o que se destaca é a relação ao reparo histórico, na intensão de estabelecer uma paridade, através da diversidade de 
possibilidades imagéticas. E o conceito de design abordado é baseado na definição epistemológica apresentada por Gustavo Bomfim (COUTO, 2014), que estão apoiadas nas formas de conhecimento que emergem das novas visões de mundo.

Sendo assim, o conceito de Design Afirmativo parte de um olhar que tem como eixo a ancestralidade, a cultura e a história dos povos africanos e da Diáspora. A abordagem tem o intuito de fazer uma configuração baseada nessas premissas e se desenvolve no cotidiano, em um espaço no qual Milton Santos chama de banal (1996), um espaço mais amplo, um espaço de todos, da humanidade e tem como elemento imagético a sua corporeidade como dimensão da sua individualidade e elemento objetivo de apresentação que demarca uma lugaridade, uma consciência de lugar, rompendo com os estereótipos construídos desde o tempo colonial, tais como: intelectualidade inferior, sexualidade exacerbada, pele suja, cabelo ruim, dentre outros.

"dentro de toda exclusão e opressão sofrida na colonização, restou às populações de descendência africana o seu corpo como forma de expressão e identificação na diáspora". (HALL, 2013, p.324).

Consequentemente a reafirmação desse corpo positivamente, interfere na subjetividade, não só do indivíduo, mas de toda a sociedade e essa visualização coloca essa memória em um espaço de disputa.

É um design crítico e de resistência com uma agenda política de transformação, pois sem esse pensamento arrisca-se a uma redução, homogeneização, e até mesmo, um apagamento pela ordem social vigente. Sendo assim, esse design dá forma a essa intenção. Cardoso diz, "Todo objeto manufaturado, por sua vez, tem como meta transformar as relações do usuário com seu entorno de modo a tirar dele algum proveito"(FLUSSEM, 2007, p.12-13). Observamos cada vez mais a legitimação desses conhecimentos através de um design, que se apresenta na estética, cultura de massa e nas ações políticas.

\section{Conclusão}

A luta dos movimentos negros no final do século $X X$ resultou em avanços importantes no começo do novo século, mostra uma ressignificação do que é ser negro para sociedade brasileira. Essa disputa pelo imaginário positivo de uma negritude passa por diversos campos, dentre os quais, o caracterizado pela união de "design + ações afirmativas" é uma peça fundamental para a popularização e reforço dos conhecimentos africanos e afrodiaspóricos ${ }^{6}$.

Assim como Stuart Hall diz (2000), a questão de identidade contemporânea tem muito mais a ver com "quem podemos nos tornar" do que exatamente, "quem nós somos" e "de onde viemos", isso passa pela representação do negro na sociedade e a mudança dessa representação, a partir de sua colocação como sujeito social na construção do discurso. Um discurso que visa reparar uma injustiça cognitiva baseada no racismo antinegro.

A construção desse negro contemporâneo, principalmente no Brasil, em que sua representação no cinema, na televisão, na moda e nas mídias de uma maneira geral é negada. Vai ser organizado através de uma proposta simbólica identitária que reconhece esse indivíduo e o coloca no mundo fortalecendo sua corporeidade e pensamento por meio de um design que

\footnotetext{
${ }^{6}$ Por afrodiáspora se deve entender toda a região fora do continente africano formada por povos africanos e seus descendentes, seja pela escravidão entre o século XV e XIX, seja pelos processos migratórios do século XX (Noguera, 2014, p.40)
} 
reconhece o seu passado e projeta-o para o futuro, através do comportamento, das vestimentas, objetos se busca a minimização das desigualdades sociais e raciais.

O Design Afirmativo é um design de postura ativa a partir do pertencimento identitário, com a intenção de contribuir para a melhora das condições da população negra se utilizando da comunicação imagética. Se o ponto de vista do futuro é dado pelos mais fracos, pelos marginalizados (SANTOS, 1996), é nesse olhar que o design afirmativo é pautado. A construção dessa identidade passa pela relação com os objetos, no intuito de dar significado a esse ideal de negro.

\section{Referências}

BAUMAN, Zygmunt. $O$ mal-estar da pós-modernidade. Rio de Janeiro: Jorge Zahar Ed.,1998.

BARBOSA, Muryatan Santana.Eurocentrismo e História: problemas e alternativas. Caderno de resumos \& Anais, 2․ Seminário Nacional de História da Historiografia. A dinâmica do historicismo: tradições historiográficas modernas. Ouro Preto: EdUFOP, 2008. Disponível em: <http://www.seminariodehistoria.ufop.br/seminariodehistoria2008/t/mury.pdf>. Acesso em: 16 nov. 2017.

COUTO, Rita; FARBIARZ, Jackeline; NOVAES, Luiza (Orgs.). Gustavo Amarante Bomfim uma coletânea. Rio de Janeiro: Rio Book's 1a Edição 2014.

DIMENSTEIN, Gilberto. Preconceito racial determina desigualdade. Folha Online, Jornalismo comunitário, 232 set. 2004.2 Disponível em <https://www1.folha.uol.com.br/folha/dimenstein/noticias/gd230904a.htm>. Acesso em: 12 dez. 2017.

FLUSSER. Vilém. O mundo codificado: por uma filosofia do design $e$ da Comunicação. São Paulo: Cosac Naify, 2007.

FUNDAÇÃO CULTURAL PALMARES. Fundação Cultural Palmares 29 anos (1988-2017). Disponível em: <http://www.palmares.gov.br/>. Acesso em: 10 dez. 2017.

GEEMA. Grupo de Estudos Multidisciplinar da Ação Afirmativa. 2008. Disponível em < http://gemaa.iesp.uerj.br/>. Acesso 15/06/2017.

GERMANO, José Willington; COSTA DA SILVA, Thalita; GALVÃO DA COSTA, Joicy Suely. Saberes ausentes: colonialismo e injustiça cognitiva. Revista Interlegere, no 7, 2010 (Programa de PósGraduação em Ciências Sociais da Universidade Federal do Rio Grande do Norte). Disponível em <https://periodicos.ufrn.br/interlegere/article/view/4678/3844>. Acessado em 15/06/2017.

GUIMARÃES, Antônio Sérgio A. Racismo e anti-racismo no Brasil. Rio de Janeiro: Editora 34, 1999.

HALL, Stuart. A identidade cultural na pós-modernidade. Rio de Janeiro: Lamparina, 2014.

HALL, Stuart. Quem precisa da identidade? In: SILVA, Tomaz Tadeu (org. e trad.). Identidade $e$ diferença: a perspectiva dos estudos culturais.. Petrópolis: Vozes, 2000. p. 103-133.

HALL, Stuart. Raça, o significante flutuante. Revista Z Cultural (PACC-UFRJ), Ano VIII, No.2, 2013. Disponível em: <http://revistazcultural.pacc.ufrj.br/raca-o-significante-flutuante\%EF\%80\%AA/> Acessado em: 10 dez. 2017.

MOEHLECKE, Sabrina. Ação afirmativas: História e debates no Brasil. Fundação Carlos Chagas, 
Cadernos

de

Pesquisa,

n.117,

2002.

Disponível

em:

<http://publicacoes.fcc.org.br/ojs/index.php/cp/article/view/550>. Acesso em: 15 de nov. 2017.

NOGUERA, Renato. Entre a linha e a Roda: Infância e educação das relações étnico-raciais. Revista do Programa de Pós-Graduação em Humanidades, Culturas e Artes - UNIGRANRIO, vol.1, n.15, p. 398-419, 2017. Disponível em: https://www.google.com.br/url?sa=t\&rct=j\&q=\&esrc=s\&source=web\&cd=1\&cad=rja\&uact=8\&ved =0ahUKEwiZsuPj68LXAhUJiZAKHVeHB7QQFggnMAA\&url=http\%3A\%2F\%2Fpublicacoes.unigranrio. edu.br\%2Findex.php\%2Fmagistro\%2Farticle\%2Fdownload\%2F4532\%2F2447\&usg=AOvVaw0wqLL _OvT7RLmYalELmi98>. Acesso em: 18 ago. 2017.

NOGUERA, Renato. 0 ensino de filosofia e a lei 10.639. 1ㅇe ed. Rio de Janeiro: Pallas: Biblioteca nacional, 2014.

OLIVEIRA, Luciano Amaral. Estudos do discurso: perspectivas teóricas. São Paulo: Parábola Editorial, 2013.

PEREIRA, Amilcar Araújo. “O Mundo Negro": a constituição do movimento negro contemporâneo no Brasil (1970-1995). Tese, Universidade Federal Fluminense, Instituto de Ciências Humanas e Filosofia, Departamento de História, 2010.

PETRUCCELLI, José Luis; SABOIA, Ana Lúcia (Orgs.). Características Étnico-raciais da População: Classificação e identidades. IBGE, Estudos \& Análises Informação Demográfica e Socioeconomica, 2013. Disponível em: <https://biblioteca.ibge.gov.br/visualizacao/livros/liv63405.pdf>. Acessado em: 27 nov. 2017.

PINHEIRO, Lisandra B. M. Negritude, apropriação cultural e a "crise conceitual" das identidades na modernidade. XXVII Simpósio Nacional de História, 2015. Disponível em: <http://www.snh2015.anpuh.org/resources/anais/39/1427821377_ARQUIVO_LISANDRATEXTOCOMPLETOANPUH2015.pdf>. Acesso em: 3 de mar. 2018.

SANTOS, Joel Rufino dos. "O Movimento Negro e a crise brasileira". In: Política e Administração, Vol.2. Julho - Setembro de 1985.

SANTOS, Márcio André de Oliveira dos. A persistência política dos movimentos negros brasileiros: processo de mobilização à 3o Conferência Mundial das Nações Unidas Contra o Racismo. (Dissertação de mestreado em ciências sociais. Rio de Janeiro, UERJ, 2005).

SANTOS, Milton Almeida. Por uma geografia cidadã: por uma epistemologia da existência. Boletim Gaúcho de Geografia, 21: 7-14, ago., 1996. Disponível em: < http://seer.ufrgs.br/bgg/article/view/38613/26350>. Acesso em: 15 de nov. 2017.

SEPPIR. Secretaria Nacional de Políticas de Promoção da Igualdade Racial. Ministério dos Direitos Humanos. Disponível em: <http://www.seppir.gov.br/>. Acesso em: 10 dez 2017.

SILVA, Joyce Gonçalves da. Corporeidade e identidade, o corpo negro como espaço de significação.Coninter3, Congresso Internaciosnal Interdisciplinar em Social e Humanidades, n.3, v. 17, p.263-275, 2014. Disponível em: <https://www.researchgate.net/profile/Joyce_Goncalves_Restier_Da_Costa_Souza/publication/3 22531117_CORPOREIDADE_E_IDENTIDADE_O_CORPO_NEGRO_COMO_ESPACO_DE_SIGNIFICACA O/links/5a5e9424a6fdcc68fa992d1b/CORPOREIDADE-E-IDENTIDADE-O-CORPO-NEGRO-COMO- 
ESPACO-DE-SIGNIFICACAO.pdf>. Acesso em: 13 out 2017.

SODRÉ, Muniz. Claro e escuros: identidade, povo e mídia no Brasil. Petrópolis, RJ: Vozes, 1999. 